\title{
Radios comunitarias desde una perspectiva indígena - La experiencia de la Organización de Comunidades Aborígenes de Nazareno, Salta-Argentina
}

\author{
Community radios from an indigenous \\ perspective - The experience of the Organization of \\ Aboriginal Communities of Nazarene, Salta-Argentinat
}

Emilia Villagra | Universidad Nacional de Salta (UNSa) Licenciada en Ciencias de la Comunicación de la Universidad Nacional de Salta (FH-UNSa) y becaria doctoral del Consejo Nacional de Investigaciones Científicas y Técnicas (Conicet), Argentina. Email: emi_villagra_02@hotmail.com

Ramón Burgos | Universidad Nacional de Salta (UNSa) Doctor en Comunicación (UNLP). Docente e investigador en la Universidad Nacional de Salta (UNSa) y en la Universidad Nacional de Jujuy (UNJu), Argentina. Codirector de la Unidad de Investigación en Comunicación, Cultura y Sociedad (UNJu). Email: monchoburgos@hotmail.com

\section{Resumen}

En este artículo pretendemos mostrar el trabajo realizado durante la elaboración de la tesis de grado "Queremos que la gente no pueda vivir sin la radio. Procesos de gestión y de construcción de contenidos en una radio comunitaria. El caso de la Organización de Comunidades Aborígenes de Nazareno (OCAN) Salta, 2014-2016"; reflexionando sobre el recorrido por las distintas facetas que tuvo que pasar la organización para la creación de la primera radio comunitaria en el territorio Qullamarka, algunas veces a pulmón y otras con el apoyo y la colaboración por parte de distintos organismos pertenecientes al Estado Nacional.

Palabras Claves: radio comunitaria; gestión; organización.

\begin{abstract}
In this article we intend to show the work done during the development of the degree dissertation "We want that people could not live without the radio. Processes of management and construction of contents in a community radio. The case of the Organization of Aboriginal Communities of Nazarene (OCAN) Salta, 2014-2016", reflecting on the path the organization had to go through in order to accomplish the creation of the first community radio of the Qullamarka territory, sometimes working our lungs out, sometimes with the support and collaboration of different agencies belonging to the National State.
\end{abstract}

Keywords: community radio; management; organization. 


\section{Introducción}

Durante los años 2014-2016, desde las cátedras Práctica en Comunicación Comunitaria e Institucional y Comunicación Popular y Alternativa de la carrera de Ciencias de la Comunicación de la Universidad Nacional de Salta, se impulsaron dos proyectos de extensión ${ }^{1}$ y un proyecto de investigación ${ }^{2}$ que tuvieron como fin acompañar y reflexionar sobre una serie de procesos comunicacionales de radios indígenas en la provincia de Salta. Por su parte, en el marco de la aplicación de la Ley 26.522 de Servicios de Comunicación Audiovisual (LSCA), se les permitió el acceso a Pueblos Originarios respaldados a través del artículo 37 que les asigna "el otorgamiento de autorizaciones a personas de existencia ideal de derecho público estatal, Universidades Nacionales, Pueblos Originarios e Iglesia Católica que se realiza a demanda y de manera directa, de acuerdo con la disponibilidad del espectro, cuando fuera pertinente". Esto impulsó la puesta en marcha de diversas emisoras indígenas con el fin de ampliar el espectro radiofónico a los sectores que históricamente han sido silenciados, siendo el Estado hasta entonces, cómplice de la mala distribución del acceso a la comunicación, considerada a partir de la Ley 26.522 un derecho humano fundamental.

En ese sentido, nuestra participación en proyectos de investigación y extensión financiados por la Universidad Pública nos ha permitido comenzar a indagar en el contexto, las demandas, las disputas y los conflictos que tiene la organización, conformando un mapeo de actores y experiencias en el territorio, que dan cuenta del difícil y complejo proceso que significa la construcción de un espacio comunicacional comunitario, alternativo y popular.

\section{Territorio y organización}

Nazareno, "un pueblo cerquita del cielo", se encuentra situado en el departamento de Santa Victoria Oeste y se ubica al noroeste de la provincia de Salta. Al norte limita con Bolivia, al sur y al oeste con la provincia de Jujuy, y al este con el departamento de Orán (Salta). Para acceder a este lugar desde la ciudad de Salta es necesario tomar la Ruta Nacional no 9 hasta llegar a la localidad de La Quiaca en Jujuy, en la frontera con Bolivia, luego se debe ascender hasta el Abra de Fundición a 5.050 metros de altitud y al final, descendiendo hasta los 3.050 metros, se encuentra el municipio de Nazareno.

El trabajo cotidiano que realizan sus habitantes está relacionado con el cuidado sanitario de los animales, la matanza y el carneo, la preparación del terreno para la siembra (dependiendo del clima), la limpieza de los canales de riego, la construcción de viviendas, la cosecha y almacenamiento de alimentos como el maíz, el choclo, la papa y la quinoa. Es por ello que la dependencia que estos tienen con respecto a los alimentos que cultivan en su tierra es lo que les permite sobrevivir a las condiciones de vida que esta región presenta, una región atravesada por la pobreza extrema que históricamente se ha conformado así, de manera estructural, por la mala distribución de las riquezas. Muchas de las comunidades no poseen luz eléctrica ni agua corriente, por lo tanto tampoco tienen 
calefacción en sus hogares, obligándolos a poseer gran cantidad de prendas de vestir para subsistir a los intensos fríos que provoca el invierno.

La Organización de Comunidades Aborígenes de Nazareno (OCAN) se conformó en el año 1994. Nuclea a 23 comunidades dentro del municipio de Nazareno3. Obtuvo la personería jurídica en el año 1998 a través del Instituto Nacional de Asuntos Indígenas. Forma parte de la región de Qullamarka ${ }^{4}$ participando de las asambleas que se realizan en dicho espacio cada tres meses. La organización emprende su trabajo a través de un coordinador, quien es el encargado de convocar a los delegados de cada comunidad para participar de las asambleas que realiza la OCAN cada dos meses. Dichos delegados representan los intereses y necesidades del pueblo y son quienes deben plantear las distintas problemáticas e inquietudes que las comunidades tienen para trabajar junto con la organización.

La organización busca ser un espacio de discusión política que apunte a la "integridad" de las personas del municipio, gestionando proyectos que posibiliten mejorar las condiciones de vida para satisfacer las necesidades básicas que cada comunidad tiene, fomentando la organización y la participación comunitaria, mejorando la producción y comercialización de alimentos que las comunidades cultivan, planteando un espacio que les permita recuperar los saberes ancestrales y la lengua materna.

\section{Camino hacia una radio propia}

La historia del "deseo" de contar con un medio de comunicación propio surge en el año 2004, cuando estudiantes de la Universidad Nacional de Córdoba llevaban a cabo un proyecto de extensión ${ }^{5}$ que tenía como objetivo poner en marcha los espacios comunicacionales del municipio de Nazareno. Allí es donde se produce el primer acercamiento que la organización tiene con la radio. En ese contexto, la comunidad reflexiona acerca del lugar y sus modos de comunicarse, la relación cultural y política existente entre los actores y espacios delimitados dentro de la comunicación comunitaria, popular y alternativa. Diez años más tarde, se inaugura la primera radio comunitaria de la zona - la FM OCAN 88.3-, en el marco de la Ley 26.522 de Servicio de Comunicación Audiovisual. Se empieza a gestionar el trámite para obtener no solo la licencia, sino también el financiamiento necesario para el equipamiento a través de los Fondos de Fomento Concursables para Medios de Comunicación Audiovisual, proyectos impulsados desde la Autoridad Federal de Servicios de Comunicación Audiovisual ${ }^{6}$.

Durante este proceso es cuando se empieza a pensar en la necesidad de contar con una radio propia, una radio que pertenezca a la OCAN y defienda los intereses de las comunidades, que sea capaz no solo de informar a las personas, sino también de brindarles un espacio que comunique sobre su realidad, que ponga en discusión cuales son los derechos que les corresponden a las comunidades indígenas y funcione como una herramienta de cambio social (GUMUCIO DAGRÓN, 2001). 
Creemos necesario poder entender el sentido profundo que la organización y las personas que la integran le atribuyen a la radio, reflexionando sobre un proceso que durante años se trabajó con distintos actores y organizaciones del campo popular. Es por eso que resulta muy interesante pensar en el rol de los medios de comunicación comunitarios, y cómo estos alentaron otras formas de poder pensar la comunicación; con relación a esto Claudia Villamayor señala que:

La radio comunitaria es un hecho cultural y parte de un enfoque de comunicación sociocultural, constructora de sentido sociopolitico, capaz de generar comunidades culturales y no sólo las marcadas por una geografía particular. Están las identidades juveniles, de movimientos sociales como el de las mujeres, los pueblos originarios, los artísticos, los grupos de hospitales psiquiátricos, cárceles, grupos de creación sonora y radioarte político, grupos universitarios, grupos sociales promotores de la diversidad de género y opciones sexuales, religiosas, laicas, radios escolares comunitarias, entre otras. Se trata, en fin, de una perspectiva politico-comunicativa y cultural de hacer radio que se define como politica y con objetivos politicos humanistas y laicos. (VILLAMAYOR, 2014, p. 92)

Por otro lado, entendemos que los procesos políticos de participación ciudadana que llevan adelante las radios comunitarias consolidan a estas como "el instrumento más atractivo para la comunicación y el desarrollo participativo. Sin duda, es la herramienta comunicacional más extendida en el mundo y el medio ideal para provocar cambios sociales" (DAGRÓN, 2001, p. 15). Provocar esos cambios sociales requiere "tomar la palabra" y cuestionarse acerca de ello. En ese sentido,

uno se pregunta si el acto de tomar la palabra no es o no debe volverse el principio
constitutivo de una sociedad: en suma, cuando la excepción asume el peso de una regla;
cuando accidente significa lo universal. Se trata entonces de una cuestión subversiva: se
cuestiona el sistema. (DE CERTEAU, 1995, p. 10)

Las radios comunitarias nacieron en Argentina como espacios de fortalecimiento en los barrios, en las comunidades y en las organizaciones sociales, como espacios sin fines de lucro que buscaban transformar su realidad a través de la participación de la audiencia y la toma de la palabra como un ejercicio para fortalecer el derecho a la comunicación y con esto la visibilización de sectores hasta el momento invisibilizados (KEJVAL, 2009). El hecho de que existan medios, que no son ni de propiedad del Estado ni de una empresa, los coloca en un lugar distinto, en un lugar donde no hay interés por el lucro, sino una necesidad por construir un canal alternativo de información con características muy distintas a los medios privados/comerciales:

Se trata de prácticas que permiten a la asociatividad, abrir espacios de libertad de expresión y ejercicio del derecho a la comunicación. Esto es así, en la medida que existe una hegemonia centralizada y centralizante que sumerge e invisibiliza voces. Por este motivo, surgen otras formas de comunicación que históricamente se han hecho eco, estrategia y recurso para viabilizar otras expresiones mayoritarias que surgen no del consumo de la cultura, sino de la apropiación de un derecho para revindicar otros derechos. (VILLAMAYOR, 2014, p. 98) 
En el caso de la FM OCAN, la radio se constituyó como un espacio de organización y participación indígena, representada por sus propios comunicadores, quienes la integran y promueven a través de los programas que la radio trasmite, tratando problemáticas que atraviesan no solo a la organización sino todas las instituciones que forman parte de él, buscando construir un medio alternativo que contemple las características que el pueblo tiene, que responda a su cultura y les permita apropiarse del espacio para trasmitir sus necesidades, sus demandas y sus propios mensajes

\section{Gestión en medios comunitarios indígenas}

Nuestros primeros acercamientos a la Organización de Comunidades Aborígenes de Nazareno comienzan a mitad del año 2014 desde la Universidad Pública, con el objetivo de cumplir con su rol extensionista para contribuir al desarrollo de una sociedad más justa y democrática. Allí nos sumamos a participar de la Mesa de Comunicación Popular de Salta y Jujuy, un espacio colectivo que se creó por iniciativa del Instituto Nacional de Tecnología Agropecuaria en el ańo 2012, nucleado en ese entonces, por distintos organismos estatales y organizaciones sociales, buscando generar una articulación entre las distintas experiencias de comunicación popular del norte argentino, vinculadas principalmente a la agricultura familiar.

Es por ello que la experiencia de trabajo que llevamos adelante en conjunto con la OCAN estuvo atravesada por la participación de diversos organismos públicos que aportaron a la construcción de la radio desde distintas perspectivas. La gestión previa a la inauguración fue un proceso que se inició desde el momento en que la organización se propuso trabajar por el funcionamiento de una radio propia. La autogestión fue el camino que tuvimos que abrirnos con el paso de los días para encontrar soluciones a los problemas que iban surgiendo, la voluntad y el esfuerzo para concretar este espacio fueron dos cuestiones fundamentales a la hora de poner las ideas en juego. Muchas veces costaba encontrar alternativas rápidas que ayudaran a conseguir financiamiento para comprar todo el equipamiento necesario para poder trasmitir, es por eso que concretarla llevó un poco más de tres ańos, justamente porque la elaboración de proyectos para conseguir dinero llevaba su tiempo y su forma, lo que también marcaba los tiempos para trabajar y organizarse.

La constancia para aportar al debate, al aprendizaje y a las prácticas de producción radiofónicas fueron fundamentales para poder concretar este proyecto, en una primera instancia viajábamos mes de por medio para acompañar los talleres que otros organismos/personas daban o para llevar desde la Universidad alguna capacitación en el marco del proyecto de extensión, apuntando a reforzar lo que se venía trabajando en otras capacitaciones. Con el paso del tiempo empezamos a profundizar nuestra práctica y a viajar todos los meses, con la intensión de acelerar la inauguración de la radio, entendiendo que los lazos con los delegados de la OCAN y las personas de las comunidades se habían afianzado, lo que nos permitía 
participar de las asambleas que realizaba la organización cada dos meses. Todas estas instancias de trabajo generaron una enorme diversidad de material teórico para pensar y entender la comunicación, para aprender a hacer radio y también para reflexionar desde distintas teorías sobre "cómo lo hacemos" y "qué sentido" le ponemos a eso que hacemos. Desde esta perspectiva encontramos similitudes en el proceso que se llevó adelante cuando Villamayor y Lamas señalan que

la radio, como toda organización, se constituye por el conjunto de sus partes (departamentos, áreas, equipos etc.) y a través de las personas (cada una con sus aportes personales y su diversidad) necesita ordenar adecuadamente sus recursos, sus esfuerzos e iniciativas. Alcanzar esta meta es el resultado de la combinación adecuada entre sueños, utopias, objetivos, recursosy posibilidades. (VILLAMAYOR y LAMAS, 1998, p. 12)

La gestión y el armado de contenidos fueron dos cuestiones que se complementaron todo el tiempo, si bien es cierto que parte de la gestión tuvo que ver con resolver tareas más burocráticas, también es cierto que esto implicaba pensar en las formas de trabajo que se iban a llevar adelante, el cómo dar esas capacitaciones y que realmente le sirvan a la comunidad, pensar en qué temas eran necesarios tratar y cuáles no, y generar, por sobre todo un espacio que permitiera discutir y repensar la gestión como una forma organizativa que contemplara a todas las comunidades y nos permitiera trabajar de manera colectiva, porque "gestionar una radio es gestionar un territorio, es ensayar y poner en situación las posibilidades populares de hacer y decidir" (TORRES y LANCE, 2014, p. 9) lo que nos obligaba a replantearnos constantemente las decisiones que tomábamos para organizarnos en función de las demandas y necesidades existentes.

El hecho de pensar en esa radio como una radio propia, autogestionada, alternativa e indígena, generaba grandes expectativas por parte de los miembros de la organización, lo que derivaba en largas jornadas de charlas y debates sobre la importancia de capacitarse para poder producir mensajes, aprender a trasmitirlos y perder la vergüenza frente al micrófono, teniendo en cuenta que era la primera vez que atravesaban por una experiencia así, ya que la mayoría de los integrantes del municipio nunca habían tenido contacto con la radio de manera directa, pero sentían curiosidad por aprender y poder usarla como un servicio para las 23 comunidades, pensada para que todos pudieran participar y tener un espacio que les permitiera enviar mensajes a sus familiares, comunicar cuando un animal estaba perdido tras los cerros, informar sobre las novedades que la organización tenía, comentar acerca de la gestión del municipio, trasmitir información relevante acerca del clima y su influencia en la producción de alimentos, pero por sobre todo como una herramienta para fortalecer los derechos indígenas, recuperar su identidad y, por ende, su cultura originaria.

La gestión del medio implicó definir el proyecto comunicacional y los distintos roles necesarios para poder sostener el espacio, entendiendo que la cuestión de la sostenibilidad no tiene recetas que se puedan aplicar 
(DAGRÓN ALFARO, 2011), sino que depende de las condiciones sociales, políticas y culturales en las que se inserta el medio. Es por ello que uno de los primeros puntos que se discutió fue la definición del comunicador indígena, al que definen como un actor social que se construye a partir de su etnia, atravesada por aspectos fundamentales que definen a los pueblos originarios, como la espiritualidad y la relación que el indígena mantiene con la pachamama (EQUIPO DE COMUNICADORES PUEBLOS ORIGINARIOS, 2012), apoyándose en la idea de comunicación con identidad, un concepto que empezó a divulgarse por distintas organizaciones indígenas previo a la aprobación de la Ley de Servicios de Comunicación Audiovisual.

[...] la expresión comunicación con identidad fue la categoría que los pueblos originarios adoptaron para definir el tipo de comunicación producida por ellos, en el proceso de consulta de la Ley 26.522. Si bien la Ley asumió la demanda que hicieron los comunicadores indigenas, no la expresó exactamente bajo esta formulación terminológica. En fechas posteriores, se puede encontrar la institucionalización del término en las convocatorias que se hacen desde la Autoridad Federal del Servicio de Comunicación Audiovisual, con el Fondo de Fomentos Concursables para Medios de Comunicación Audiovisual, o en las publicaciones que se generan desde espacios como Encuentro Nacional de Organizaciones Territoriales de Pueblos Originarios (ENOTPO), Coordinadora de Comunicación Audiovisual Indígena (CCAIA), y en los foros, seminarios o exposiciones que se llevan adelante con el propósito de promover la gestión de medios indigenas. (LIZONDO, 2015, p. 114)

A partir de estos debates tan profundos y necesarios, la organización consolidó un grupo de comunicadores, en su mayoría voluntarios que tenían interés por aprender y trabajar en medios, para capacitarlos y ofrecerles la oportunidad de viajar a las distintas actividades, talleres, foros y encuentros de comunicación que se estaban realizando en todo el país en el marco de la aplicación de la Ley, impulsados por el Instituto Nacional de Tecnología Agropecuaria y la Autoridad Federal de Servicios de Comunicación Audiovisual.

A su vez, la organización formuló cuatro proyectos para el Fondo de Fomento Concursable para Medios de Comunicación Audiovisual, para gestionar e impulsar la sostenibilidad económica, social e institucional del proyecto. Los cuatro proyectos que se presentaron fueron aprobados y permitieron la compra de equipamiento y el pago de honorarios a capacitadores y talleristas que colaboraron en el proceso de gestión para implementar la radio. En estos casos, el primer proyecto fue el de Equipamiento. Allí se compró la consola, el excitador, el trasmisor, micrófonos y una computadora de escritorio. El segundo proyecto ganado fue el de Gestión de Medios, en el año 2014, en el cual se contempló un plan de mejoras para la gestión contable, la coordinación y las relaciones institucionales con los distintos actores del municipio, y finalmente en el año 2015, se presentaron dos proyectos en forma simultánea, uno nuevamente por la línea de Equipamiento para poder construir la torre y la antena, y el segundo por la línea de Producción de Contenidos para producir un programa informativo 
semanal. Ambos proyectos fueron aprobados en noviembre del ańo 2015, y se ejecutó el primer desembolsó el 22 de diciembre del mismo año, dos días antes de que el gobierno de Mauricio Macri interviniera la Autoridad de Servicios de Comunicación Audiovisual, organismo encargado de pagar dichos proyectos.

Todo este proceso de organización, gestión y ejecución de proyectos logró estabilidad tanto en la organización como en los vínculos con instituciones y organizaciones de todo el municipio, apelando a estrategias participativas que permitieron consolidar un proyecto comunicacional colectivo atravesado por la alternatividad, la cooperación de organismos provinciales y nacionales, y la organización comunitaria como motor fundamental para construir desde la puesta en común y el diálogo, asumiendo que

la gestión no puede entenderse apenas como la adopción de una medida coyuntural sobre este o aquel aspecto, sino como la suma de los elementos y factores que van conformando paso a paso la decisión. La gestión, por lo tanto, radica en todo el proceso y en todos los elementos que se coordinan hasta llegar a establecer los objetivos de una acción, los pasos para ponerla en práctica y los recursos que se necesitan. $Y$, por supuesto, la forma coordinada de evaluar el cumplimiento de lo que se ha decidido. (LAMAS y VILLAMAYOR, 1998, p. 15)

\section{Producción de contenidos desde una perspectiva indígena}

Producir contenidos fue lo que consolidó el proyecto comunicacional, allí se encontró un lugar de entusiasmo que empezó a cosechar todo el trabajo que la gestión había realizado para tener los equipos necesarios. Cuando se pusieron en juego las herramientas radiofónicas, la voz, la música, los efectos y el silencio, el murmullo se transformó en palabras (MATA, 2009).

El concurso de los Fondos de Fomento Concursable para Medios de Comunicación Audiovisual, por la línea de producción radiofónica, exigía grabar un demo que simulara un ejemplo de lo que sería el programa radial por el que se estaba solicitando financiamiento, esto obligó a la comunidad a pensar en un primer programa al aire, con sus respectivos bloques y edición de los mismos. Es por ello que para empezar a trabajar sobre esto se planteó la necesidad de pensar en primer lugar el objetivo general: ¿qué quiero comunicar? y ¿a quién estará dirigido lo que quiero comunicar? Con estas dos preguntas disparadoras se reflexionó sobre la temática a abordar y la importancia que esta tuviese para la comunidad en general.

A partir de allí pudimos armar una estructura a modo de "esqueleto" que nos permitiera desglosar el programa con sus tiempos marcados, música, efectos, voces y silencios necesarios. Para ello definimos los roles: conductor, operador técnico, corresponsales, productor etc., y discutimos qué cosas haría cada uno y cómo las haría.

En este sentido, se planteó un programa semanal que pudiese discutir las distintas problemáticas que la comunidad atraviesa, entre ellas, la propiedad de la tierra, el agua, la luz, la siembra y la cosecha. Por lo tanto, durante nuestra 
participación trabajamos para consolidar un espacio que nos permitiera utilizar a la radio como una herramienta de participación política, y así resolver de manera colectiva los conflictos y hechos que ocurren en el pueblo, fundamentalmente pensando en que, como contemplaba la convocatoria, poder fortalecer vínculos y tratar las cuestiones más relevantes que ocurren en las comunidades.

El programa se llamó "La Pitajla”, nombre que se refiere a un pájaro típico de la zona, que según los ancianos del pueblo "llega para anunciar algo". Este proyecto contemplaba la posibilidad de pagar honorarios a tres personas, conductor, operador y corresponsales comunitarios, y a su vez, contemplaba tres talleres de edición y producción radiofónica, lo que le permitía a la comunidad seguir capacitándose, por lo que se decidió seguir trabajando sobre el uso de las herramientas, es decir, por un lado aprender a escribir guiones, pensando en la estructura del programa; y por otro lado, aprendiendo a manipular los equipos (computadoras, consolas, micrófonos, parlantes, proyector etc.) para poder entender su funcionamiento.

A partir de este proceso de aprendizaje, la radio empezó a ser manipulada por referentes de la organización y miembros de la comunidad que encontraban allí una herramienta pedagógica para mejorar la lecto-escritura, demostrando como un medio de comunicación alternativo contribuye doblemente al empoderamiento social, por un lado como "un potencial educativo por el proceso de organización popular y los mecanismos de planeación, producción y gestión. Y por el contenido de los mensajes que transmiten" (KROHLING PERUZZO, 2001, p. 89).

Por lo tanto, producir contenidos desde estas experiencias demuestra "claramente que no hay comunicación alternativa y popular sin propuesta de proyecto alternativo de sociedad; que son los espacios políticos y democráticos los que definen la viabilidad de ese tipo de comunicación” (FESTA, 1986, p. 29).

\section{Conclusiones}

Durante los años de trabajo que compartimos con la comunidad pudimos reconocer cómo la organización se reconoce como un espacio comunitario, esto implica una forma de verse en el mundo, de construir sentido y de mostrarse a partir de sus propios modos y formas de pensar, asumiendo y ejerciendo la comunicación desde la cosmovisión andina. Es por ello que nuestro acercamiento fue un proceso de descubrimiento, adentrarnos en la organización implicó generar la participación de todos los sectores del municipio, buscar formas y estrategias que apuntaran a consolidar un grupo de trabajo dispuesto no solo a hacer comunicación comunitaria, popular y alternativa, sino a discutirlas desde sus propias prácticas y saberes con el objetivo de implementar un medio de comunicación desde la ruralidad.

Otro punto interesante que aparece en la organización y está muy relacionado con los principios básicos de la comunicación comunitaria, popular y alternativa es la política como una forma de organización trascendental para apuntar a la transformación social (MATA, 2009). De esta manera, 
entendemos que los procesos de construcción de una radio comunitaria no escapan a la relación de lo comunicacional, lo político y a los procesos de gestión que allí se consolidan, permiten pensar que "cuando encaramos el tema de la gestión sabemos que estamos a punto de tomar una decisión político institucional que seguro nos llevará a una revisión de casi todo lo que hacemos" (LAMAS y VILLAMAYOR, 1998, p. 5).

¿Qué significa crear un medio de comunicación autogestionado por la organización más importante del municipio? Significa la posibilidad de poder acercarse a pesar de las distancias terrenales que los atraviesan, de generar un espacio capaz de discutir las problemáticas que las comunidades atraviesan y necesitan resolver. La dimensión de los problemas que existen en esos espacios son muy distintos a lo que uno puede tener en la ciudad, poder acceder al agua corriente, a la luz eléctrica y al gas, es un enorme logro para quienes durante años viven sin esos servicios. La radio vino a conquistar eso, a poner en discusión esas necesidades, a juzgar a quien tenga que hacerlo y a reconocer a quien se lo merezca, públicamente.

Cientos de personas participan de ese espacio, trabajadores rurales, pequeños y medianos productores, asociaciones, organizaciones, instituciones, docentes de las escuelas, que vienen desde muy lejos para dar clases en los alrededores del municipio, sin importarles la distancia, solo por la posibilidad de colaborar y formar parte de un espacio que está en constante crecimiento, que necesita de la fuerza de los de afuera para no quedar excluido del pleno ejercicio del derecho a la comunicación

Todo eso es lo que la radio se propone, ser un espacio político que informe sobre la realidad del pueblo, que anuncie sobre cuestiones relevantes para la comunidad, que permita que los servicios como la ambulancia, el cobro de jubilaciones y pensiones, las subas de impuestos, la falta de luz y agua, el mantenimiento en las escuelas, se discutan y se conquisten por medio de la palabra tomada, de la exigencia del pueblo.

La presencia de medios comunitarios, tanto en zonas urbanas como rurales, funciona como herramienta para compartir conocimientos, construir y debatir política, poner en discusión la desventaja que ciertos grupos sociales tienen en relación a otros por las condiciones sociohistóricas y la falta de oportunidades existentes (VILLAMAYOR, 2014), funcionando no solo como medios para trasmitir mensajes, sino como instrumentos para contribuir al proceso de la toma de conciencia de los derechos y mejorar las condiciones de vida de la población (GUMUCIO DAGRÓN, 2004).

Los medios sin fines de lucro rompen con la lógica de los medios hegemónicos, gestionan sus propias formas de organización apelando a la comunicación como una estrategia de transformación, buscando generar visibilidad social, acceso y participación de la comunidad como 
motor fundamental para llevar adelante su proyecto (LÓPEZ VIGIL, 1995), legitimando la voz propia en un contexto de múltiples voces que les permita incidir en el desarrollo de la zona a partir del ejercicio pleno del derecho a la comunicación como un derecho legítimo que les corresponde a todas las personas, porque en definitiva, creemos, como sostiene Washington Uranga, que:

Hay, en numerosos actores, la convicción creciente de que gran parte de la suerte de la democracia se juega hoy en el ámbito de la comunicación. Y que defender la pluralidad de voces y la diversidad de miradas es inseparable de la lucha política. Comunicación y politica son dos caras de una misma moneda denominada democracia (URANGA, 2016, p. 1).

\section{Bibliografía}

ASOCIACIÓN DE COMUNIDADES ABORÍGENES DE NAZARENO. La hostería que convertimos en albergue estudiantil. OCAN, 2012.

DAGRÓN ALFARO, Gumucio. Arte de equilibristas: La sostenibilidad de los medios comunitarios. 2011.

. Haciendo Olas: Historias de comunicación participativa para el cambio social. La Paz: Plural Editores, 2001.

DE CERTEAU, Michel: La toma de la palabra y otros escritos políticos. México: ITESO, 1995.

DOYLE, María Magdalena. Los medios de comunicación en las luchas de los pueblos indígenas. Abordaje desde los estudios sobre comunicación en América Latina. Tesis de Maestría en Comunicación y Cultura Contemporánea, Centro de Estudios Avanzados, Universidad Nacional de Córdoba, 2013.

EQUIPO DE COMUNICADORES DE PUEBLOS ORIGINARIOS. Aportes para la construcción del modelo de comunicación indígena en Argentina. Comunicación con identidad. INAI, 2012.

FESTA, Regina. Movimientos sociales, comunicación popular y alternativa. In: Comunicación popular y alternativa. Colección Comunicación n. 4, p. 9-29. Buenos Aires: Ediciones Paulinas, 1986.

GRIMSON, Alejandro. Comunicación y configuraciones culturales. Buenos Aires: Universidad Nacional de San Martín, 2014.

KAPLÚN, Gabriel. La comunicación comunitaria, en AAVV: Medios de comunicación. El escenario iberoamericano. Madrid: Fundación Telefónica y Ariel, 2007.

KEJVAL, Larisa. Truchas: Los proyectos politicos-culturales de la radios comunitarias, alternativas y populares argentinas. Buenos Aires: Prometeo Libros, 2009. 
KROHLING PERUZZO, Cicilia. Comunicación comunitaria y educación para la ciudadanía. Revista Signo y Pensamiento, n. 38, p. 82-93. Santafé de Bogotá, Facultad de Comunicación y Lenguaje, Pontificia Universidad Javeriana, 2001.

LAMAS, Ernesto y VILLAMAYOR, Claudia. Gestión de la radio comunitaria y ciudadana. AMARC, 1998.

LIZONDO, Liliana. Comunicación con identidad o comunicación comunitaria. El caso de la FM La Voz Indígena. Tesis de Maestría en Planificación y Gestión de la Comunicación. Universidad Nacional de La Plata, 2015.

LÓPEZ VIGIL, José. ¿Qué hace comunitaria a una radio comunitaria? Revista Chasqui, n. 52, CIESPAL. Ecuador, Quito. 1995.

MARTÍNEZ, Analía; MÜLLER, Ana y RUBINO, Andrés. Nazareno en el aire. Sistematización de una experiencia de Comunicación Popular. Tesis de Licenciatura en Comunicación Social, Universidad Nacional de Córdoba, 2007.

MATA, María Cristina. Comunicación comunitaria en pos de la palabra y la visibilidad social, In: ÁREA DE COMUNICACIÓN COMUNITARIA (compiladores): Construyendo comunidades... Reflexiones actuales sobre comunicación comunitaria. Buenos Aires: La Crujía y Universidad Nacional de Entre Ríos, 2009.

TORRES, Federico y LANCE, Florencia. Sembramos palabras, cosechamos derechos. Encuentro de Comunicación en los Territorios de Latinoamérica y el Caribe. Buenos Aires: INTA ediciones. Colección Institucional, 2013.

URANGA, Washington. Política y comunicación, caras de la misma moneda. Página 12, 2016.

VILLAMAYOR, Claudia. Las radios comunitarias, gestoras de procesos comunicacionales. Buenos Aires, 2011-2014. Mediaciones, \#12. Bogotá, julio del 2014.

VILLAGRA, Emilia. Queremos que la gente no pueda vivir sin la radio. Procesos de gestión y de construcción de contenidos. El caso de Organización de Comunidades Aborigenes de Nazareno (OCAN). Salta, 2014-2016. Tesis de Licenciatura en Comunicación Social, Universidad Nacional de Salta, 2016.

\section{Notas}

1. Los Proyectos, dirigidos por Ana Müller y codirigidos por Ramón Burgos, son "Hilvanando redes en comunicación comunitaria. Talleres de apoyo a organizaciones sociales en el marco de la Mesa de Gestión de Comunicación Popular de Salta y Jujuy" (2014) e "Hilvanando redes en comunicación comunitaria. Parte II. Talleres de apoyo a organizaciones sociales en el marco de la Comunicación Popular de Salta” (2015).

2. Proyecto de Investigación Tipo B n ${ }^{\circ}$ 2.228: "Comunicación popular y alternativa en contextos de frontera. Parte 2. Mapeo de actores y experiencias en sectores populares de Salta”, dirigido por Ramón Burgos. Consejo de Investigaciones/Universidad Nacional de Salta (2014-2016). 
3. Las 23 comunidades son: Nazareno, Campo de la Cruz, Poscaya, Monoabra, San Marco de Trigo Uayko, Paltorco, Santa Rosa, Campo la Paz, San José del Aguilar, Santa Cruz del Aguilar, San Francisco de Tuc Tuca, Pabellón, Campo Grande de Bacoya, San Isidro de Bacoya, Bacoya, El Molino, Río Blanco, Campo Grande de Río Blanco, Quellotikar, Cuesta Azul, San Marcos de Nazareno, Laguna y El Milagro.

4. Es la máxima organización como sistema de gobierno a nivel del Pueblo Kolla que coordina a las Organizaciones y Comunidades Kollas autónomas de Salta, nucleada por las siguientes organizaciones la Unión de Comunidades Aborígenes Victoreñas, la Asociación de Comunidades Aborígenes de Nazareno, el Consejo Indígena Kolla de Iruya, la Comunidad Indígena Alta Cuenca del Río Lipeo Toldos y la Comunidad Indígena del Pueblo Kolla Tinkunaku.

5. Proyecto de extensión universitaria "Capacitación y puesta en marcha de los espacios comunicacionales del Municipio de Nazareno" en el Programa de Becas de la Secretaría de Extensión de la Universidad Nacional de Córdoba (UNC).

6. Ex organismo encargado de la regulación y aplicación de la LSCA, intervenido por el gobierno de Mauricio Macri en diciembre del 2015 a través de los decretos 13 y 267. 